\title{
Physicochemical characterization of two deproteinized bovine xenografts
}

\begin{abstract}
Thais Accorsi-Mendonça ${ }^{(a)}$ Márcio Baltazar Conz ${ }^{(b)}$ Teresa Cristina Barros ${ }^{(c)}$ Lídia Ágata de Sena ${ }^{(\mathrm{d})}$ Glória de Almeida Soares ${ }^{(e)}$ José Mauro Granjeiro(f)
\end{abstract}

(a) MSc in Endodontics, Department of Endodontics, School of Dentistry of Bauru, University of São Paulo, Bauru, SP, Brazil.

(b) PhD, Metallurgy and Materials Engineering Program (COPPE), Federal University of Rio de Janeiro, RJ, Brazil.

(c) PhD, Health Science Institute, Paulista University, Bauru, SP, Brazil.

(d) $\mathrm{PhD}$, Scientific Metrology Directory (Inmetro), Duque de Caxias, RJ, Brazil.

(e) PhD, Metallurgy and Materials Engineering Program (COPPE), Federal University of Rio de Janeiro, RJ, Brazil.

(f) $\mathrm{PhD}$ in Cell and Molecular Biology, Biology Institute, Fluminense Federal University, RJ, Brazil.

\begin{abstract}
Calcium phosphate salts, or more specifically hydroxyapatite, are products of great interest in the fields of medical and dental science due to their biocompatibility and osteoconduction property. Deproteinized xenografts are primarily constituted of natural apatites, sintered or not. Variations in the industrial process may affect physicochemical properties and, therefore, the biological outcome. The purpose of this work was to characterize the physical and chemical properties of deproteinized xenogenic biomaterials, Bio-Oss (Geistlich Biomaterials, Wolhuser, Switzerland) and Gen-Ox (Baumer S.A., Brazil), widely used as bone grafts. Scanning electron microscopy, infrared region spectroscopy, X-ray diffraction, thermogravimetry and degradation analysis were conducted. The results show that both materials presented porous granules, composed of crystalline hydroxyapatite without apparent presence of other phases. Bio-Oss presented greater dissolution in Tris- $\mathrm{HCl}$ than Gen-Ox in the degradation test, possibly due to the low crystallinity and the presence of organic residues. In conclusion, both commercial materials are hydroxyapatite compounds, Bio-Oss being less crystalline than Gen-Ox and, therefore, more prone to degradation.
\end{abstract}

Descriptors: Dental implantation; Hydroxyapatite; Chemical analysis; Physical analysis.
Corresponding author:

José Mauro Granjeiro

Outeiro de São João Baptista, s/n.

Campus do Valonguinho

Niterói - RJ - Brasil

CEP: 24020-150

E-mail: jmgranjeiro@vm.uff.br 


\section{Introduction}

Calcium phosphate salts, in particular hydroxyapatite (HA), are materials of great interest for treatment of osseous deficiencies due to their biocompatibility and osteoconduction property. ${ }^{1}$ Grafts of xenogenic origin have been widely studied due to abundant sources and accessible processing costs. However, bovine bone processing should be quite well controlled in order to avoid disease transmission, ${ }^{2}$ and to assure adequate physicochemical properties for the intended use. ${ }^{3}$

It is important to mention that the structure of apatite is similar among different species. ${ }^{4}$ Several papers in the literature have shown the biocompatibility of deproteinized bovine matrix as bone graft material, ${ }^{5-7}$ which, besides providing a supportive structure for osteoconduction, releases calcium and phosphate ions essential for osteogenesis. ${ }^{8}$

The presence of pores in bone graft biomaterials has been shown as a requisite of great importance for repairing osseous deficiency, favoring the osteoconduction through osseous growth also inside the pores. ${ }^{9,10}$ In order to allow the penetration of repairing tissue and osseous neoformation in the pores, they should be greater than $100 \mu \mathrm{m} \cdot .^{11-13}$

Bio-Oss $^{\circledR}$ (Geistlich Biomaterials, Wolhusen, Switzerland) is a widely studied bovine xenograft consisting of a mineral osseous matrix obtained after the removal of the organic components of medullar bovine bone during a thermal treatment at $300^{\circ} \mathrm{C} . .^{14}$ Another bovine xenograft available in the Brazilian market is Gen-Ox ${ }^{\circledR}$ (Baumer S.A., São Paulo, Brazil) obtained through deproteinization at high temperatures (between 950 and $1,000^{\circ} \mathrm{C}$ ). The increased processing temperature enhances material crystallinity ${ }^{4,15}$ being also concurrent with the decomposition of the hydroxyapatite in other phases like tricalcium phosphate (TCP). The most crystalline biomaterial will be the least degradable, but the presence of other phases (usually more soluble than HA) may compensate or null this effect. ${ }^{16}$ The correct indication of a biomaterial shall depend on its physicochemical properties. Thus, the aim of this study was the physicochemical characterization of the products Bio-Oss and Gen-Ox, which are both deproteinized xenografts used as bone grafts.

\section{Material and Methods Materials}

The two commercial biomaterials used in this study derived from inorganic medullar bovine bone: 1) Bio-Oss, consisting of granules (250 to $450 \mu \mathrm{m}$ ) deproteinized at $300^{\circ} \mathrm{C}$, according to the manufacturer's data; 2) Gen-Ox, consisting of granules (with particles from 250 to $1,000 \mu \mathrm{m}$ ) deproteinized at $950-1,000^{\circ} \mathrm{C}$, according to the manufacturer's data (Baumer S.A. - Brazil, Registration at the Ministry of Health No. 10345500001).

\section{Physicochemical characterization}

Morphological characterization of the materials was carried out through scanning electron microscopy (Zeiss, model DSM 940A, Oberkochen, BadenWürttemberg, Germany) operating at $20 \mathrm{kV}$ of electrons acceleration. The presence of residues from the organic phase or different species of phosphate was assessed through the use of thermogravimetry and infrared spectroscopy, respectively. Thermogravimetry was performed from 50 to $950^{\circ} \mathrm{C}$ with a heating rate of $10^{\circ} \mathrm{C} /$ minute in a dynamic atmosphere of nitrogen $\left(50 \mathrm{ml} \mathrm{min}{ }^{-1}\right)$ (TA Instruments, model TGA 2950 , coupled to a thermal analyzer of TA Instruments, Model TA 2000), while Fourier-transformed infrared spectroscopy (FTIR) was obtained in a Perkin-Elmer (model 1000, Waltham, Massachusetts, USA) equipment.

In order to identify the crystalline phases in the xenografts, an X-ray diffractometer (DRX-Miniflex, Rigaku, Tokyo, Japan) was operated at $30 \mathrm{kV}$, $15 \mathrm{~mA}$ and radiation $\mathrm{CuK} \alpha$, and the data was collected from $5-100^{\circ} 2 \theta$. The crystallinity of the materials was determined from the DRX patterns according to the methodology proposed by $\operatorname{Landi}^{17}$ (2000); whereas the rate of degradation was determined threefold using protocol ISO/FDIS 10993-14:2001 (in buffer Tris-HCl, $\mathrm{pH} 7.3$ for 120 hours).

\section{Results}

Figure 1 shows the morphology of the materials studied. Bio-Oss presents particles of regular dimensions with canaliculus and ridge (Figure 1, A - D); the presence of micrometric fragments is also observed. The pores are sized 20-200 $\mu \mathrm{m}$ (Figure 1A). 

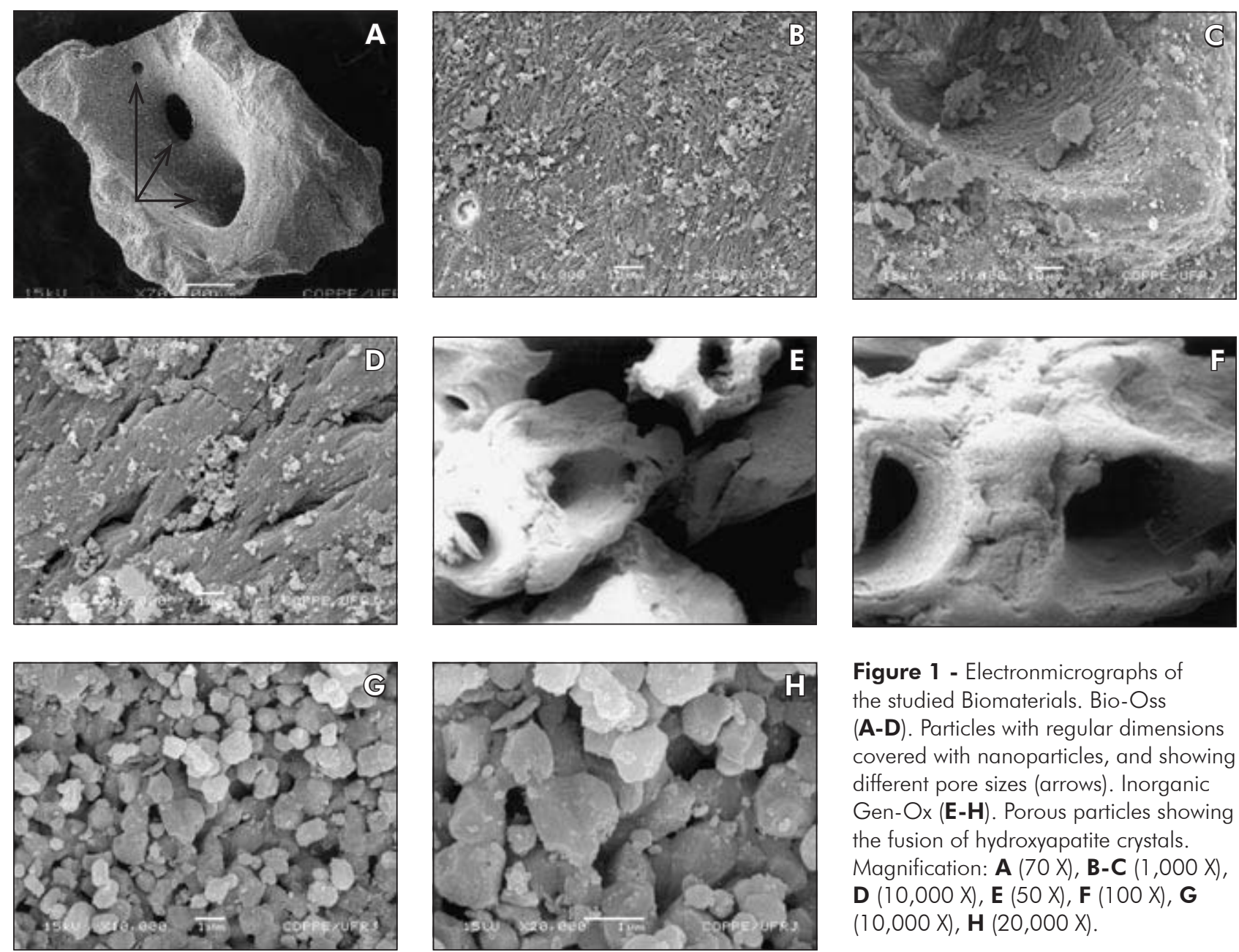

Figure 1 - Electronmicrographs of the studied Biomaterials. Bio-Oss (A-D). Particles with regular dimensions covered with nanoparticles, and showing different pore sizes (arrows). Inorganic Gen-Ox (E-H). Porous particles showing the fusion of hydroxyapatite crystals. Magnification: A (70 X), B-C $(1,000 X)$, D $(10,000 X), \mathbf{E}(50 X), \mathbf{F}(100 X), \mathbf{G}$ $(10,000 X), \mathbf{H}(20,000 X)$.

Inorganic Gen-Ox (Figure 1, E - H) also looks porous (Figure 1, E and F); when magnified (Figure 1, $\mathrm{G}$ and $\mathrm{H}$ ), the coalescence of the grains taken place during the calcination of the material at high temperatures can also be seen.

In the Fourier Transform infrared spectroscopy (FTIR), bands can be identified in the wavelength ranges of 1,554-1,569, 1,400-1,420 and $850 \mathrm{~cm}^{-1}$ corresponding to the functional group $\mathrm{CO}_{3}^{-2}$ of $\mathrm{HA}$ for Bio-Oss (Graph 1A). The phosphate group appears in both materials, but Gen-Ox (Graph 1B) presents better-defined bands between 600 and $1,100 \mathrm{~cm}^{-1}$. Bands around $3,571 \mathrm{~cm}^{-1}$ are also highlighted indicating the presence of the structural O$\mathrm{H}$ stretch, as well as bands in 1,172, 1,088, 1,025 and $963 \mathrm{~cm}^{-1}$, indicating the presence of $\mathrm{PO}_{4}^{-3}$ groups.
Bio-Oss and Gen-Ox thermogravimetric analysis (Graph 1, C and D, respectively) showed the materials' loss of mass due to the increase in temperature. Bio-Oss' loss of mass was about 2.6, 0.5 and $2.4 \%$ between $30^{\circ} \mathrm{C}$ to $420^{\circ} \mathrm{C}, 420^{\circ} \mathrm{C}$ to $635^{\circ} \mathrm{C}$ (temperature range between loss 1 and 2) and $630^{\circ} \mathrm{C}$ to $950^{\circ} \mathrm{C}$, respectively. The residual mass at $950^{\circ} \mathrm{C}$ was $94.3 \%$. Gen-Ox presented loss of mass at about $0.35 \%$ between the initial temperature and $384^{\circ} \mathrm{C}$, increasing up to $0.6 \%$ from $665^{\circ} \mathrm{C}$ to $950^{\circ} \mathrm{C}$, resulting in a residual mass of $99.4 \%$.

In the patterns obtained for X-ray diffraction (Graph 1, E-F), the major peaks identified were related to synthetic HA that according to card data JCPDS 9-432 (JCPDS-ICDD1, 1992) are placed at $2 \theta=32,33$ and $26^{\circ}$, with relative intensity of 100 , 60 and $40 \%$, respectively. From X-ray diffraction 

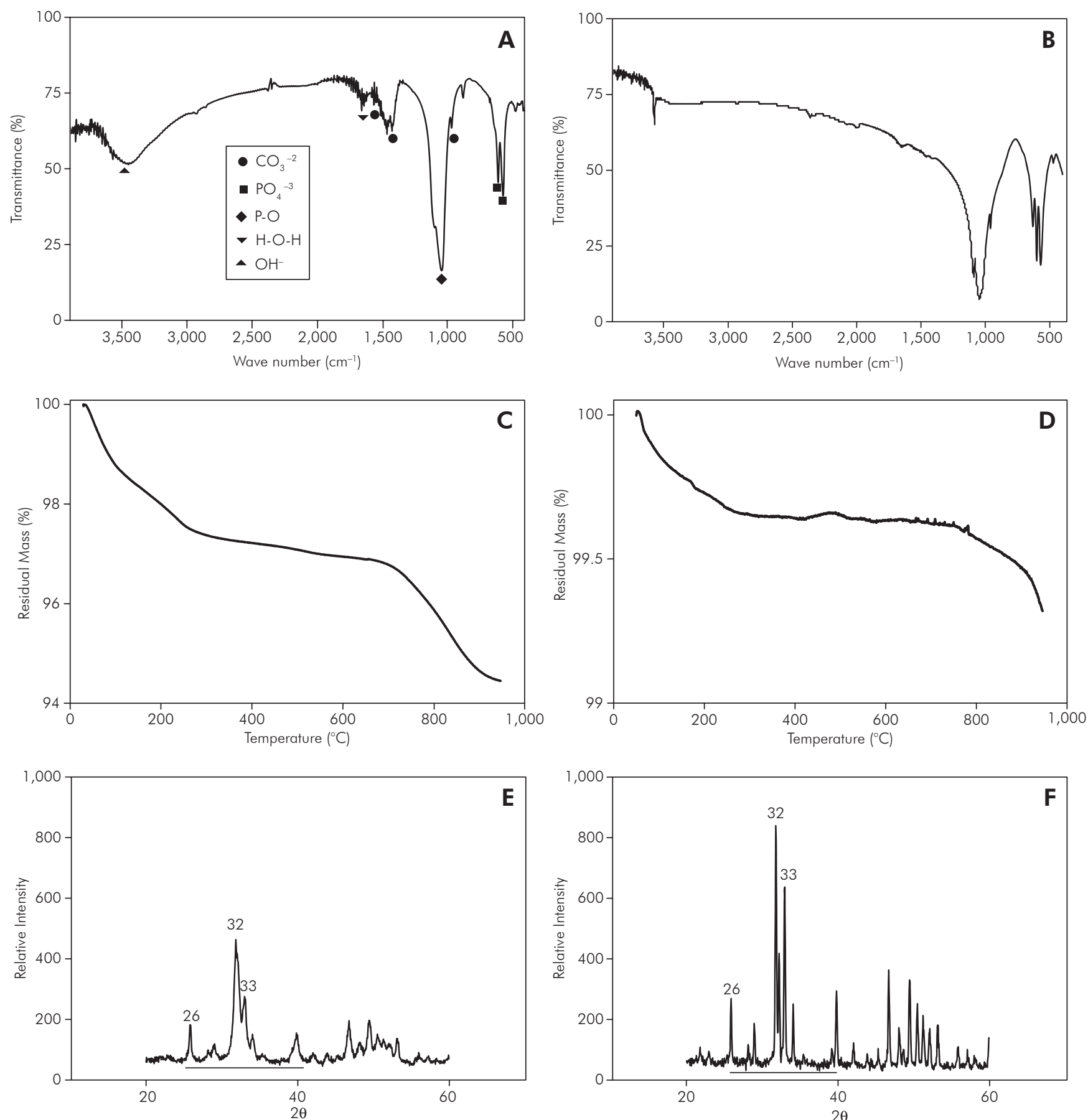

Graph 1 - Physico-chemical characterization of the xenograft implants. Fourier Transform Infrared Spectroscopy (FTIR) indicates hydroxyapatite characteristic bands for Bio-Oss (A) and Inorganic Gen-Ox (B). Thermogravimetric analyses carried out for Bio-Oss (C, initial mass: $11.01 \mathrm{mg}$ ) and Inorganic Gen-Ox (D, initial mass: $17.88 \mathrm{mg})$. X-Ray diffraction for Bio-Oss (E) and Inorganic Gen-Ox (F).

patterns the crystallinity was determined ${ }^{17}$ for each material, resulting in $40 \%$ and $96 \%$ for Bio-Oss and Gen-Ox, respectively.

The degradation test in Tris- $\mathrm{HCl}(120 \mathrm{~h}, \mathrm{pH}$ 7.3, $37^{\circ} \mathrm{C}$ ) indicated the loss of mass, the average of $4.7 \%$ ( \pm 1.61$)$ for Bio-Oss; however, no alteration of Gen-Ox mass was detected after 120 hours of degradation assay. 


\section{Discussion}

Both materials analyzed are classified as xenografts from inorganic bovine bone, and are indicated as bone defect filling materials ${ }^{18,19}$ due to their osteoconductive properties. ${ }^{5,7}$ The study about synthetic and natural apatites has shown that the material degradation rate affects the biological response to the material. ${ }^{20-22}$ Recent studies have shown that fast absorption of the biomaterial may jeopardize adequate repair. ${ }^{20} \mathrm{On}$ the other hand, non-resorbable materials can make some clinical procedures like grafts unfeasible. ${ }^{23}$ Thus, the processing way used by the manufacturers of natural and synthetic apatites affects both the physicochemical properties and the degradation rate of these biomaterials, possibly affecting bone repair. ${ }^{10,24}$

It was observed through scanning electron microscopy that both materials presented pores on their surfaces (Figure 1). The degree of microporosity depends on the compaction method of the starting powder and the temperature of synthetic materials or the use of natural materials on which the pores were biologically designed. The presence of pores in the granules increases the surface area of the xenograft material, favoring osteoconduction, enabling bone growth also in the pores. ${ }^{10}$ Porosity was similar in both materials, but the effect of increased temperature of sintering over the coalescence of apatite crystals is clear for Gen-Ox (Figures $1 \mathrm{G}$ and $1 \mathrm{H}$ ).

Infrared spectral analysis has shown that both Bio-Oss and inorganic Gen-Ox have typical HA bands. ${ }^{3,24,25}$ Bands resolution is better in Gen-Ox, suggesting high crystallinity, and no bands related to other compounds are observed. Preliminary data about material crystallinity may be obtained through infrared spectrum, especially from the bands that are in the $590-610 \mathrm{~cm}^{-1}$ and $1,000 \mathrm{~cm}^{-1}$ regions. ${ }^{3,16}$ Diffractograms of the materials assessed confirm the presence of hydroxyapatite (according to ICDD data, 9-432); however, again, the bands have better resolution for Gen-Ox. Wide bands observed in the Bio-Oss diffractogram may be related to the different characteristics of the material, like the presence of non-crystalline phases (like organic residues), nanometric dimensioned crystals or defective powder structure. . $^{15,24,25}$

The loss of mass (nearly fourfold higher than that of Gen-Ox) observed in the thermogravimetric assay suggests the presence of residual organic material in Bio-Oss graft (around 3\%). As it is expected for calcinated apatites (treatment temperature above $900^{\circ} \mathrm{C}$ ), Gen-Ox showed a loss of mass above $700^{\circ} \mathrm{C}$ only; however, this loss is virtually none, about $0.3 \%$ of the sample. No reflections related to other phases of calcium phosphates were detected. It was confirmed through Landi's ${ }^{17}$ (2000) method that Gen-Ox presented higher crystallinity than Bio-Oss, which confirmed the results of infrared and morphology of the crystals through scanning electron microscopy. This result is coherent with the calcination process to which it was submitted, since crystallinity is directly proportional to the processing temperature of the biomaterial. According to the manufacturers' data, Bio-Oss is processed in a lower temperature than Gen-Ox, 300 and $1,000^{\circ} \mathrm{C}$, respectively. The effect of processing temperature is related to the elimination of carbonate content in the bone, which happens at temperatures above $400^{\circ} \mathrm{C}$ only. ${ }^{4,15}$

Data about materials crystallinity is important, as the bioabsorption rate shall be compatible with the repairing process of the recipient tissue. Calcium phosphates solubility depends on the relation $\mathrm{Ca} / \mathrm{P}$ and, for the same composition, it depends on the crystallinity degree; so less crystalline materials are more soluble. ${ }^{4}$ Therefore, the presence of second phases (usually more soluble than HA) may compensate or null this effect..$^{15}$ In this case there was no composition effect of the HA, prevailing the effect of crystallinity in in vitro degradation. Thus, the degradation test indicated the loss of mass, at an average of $4.7 \%( \pm 1.61)$ for Bio-Oss, while no alteration of mass was detected in Gen-Ox.

The results suggest that the content of non-crystalline phases, probably organic matter and carbonate, identified through thermogravimetric, infrared and X-ray diffraction analyses, generates a biomaterial of lower crystallinity and, consequently, more prone to degradation. Thus, the processing temperature may be a way to change the physicochemical properties of the material, producing materials with different reabsorption levels.

\section{Conclusions}

Both commercial materials are hydroxyapatite compounds. Bio-Oss is less crystalline than Gen-Ox 
and is, therefore, more prone to degradation.

\section{Acknowledgments}

The authors would like to acknowledge the fi-

\section{References}

1. Kostopoulos L, Karring T. Regenerations of the sagittal suture by GTR and its impact on growth of the cranial vault. J Craniofac Surg. 2000;11(6):553-61.

2. Wenz B, Oesch B, Horst M. Analysis of the risk of transmitting bovine spongiform encephalopathy through bone grafts derived from bovine bone. Biomaterials. 2001;22(12):1599-606.

3. Conz MB, Granjeiro JM, Soares GA. Physicochemical characterization of six commercial hydroxyapatites for medical-dental applications as bone graft. J Appl Oral Sci. 2005;13(2):136-40.

4. Le Geros RZ. Calcium phosphates in oral biology and medicine. Basel: Karger; 1991. Monographs in oral science. v. 15.

5. Masters DH. Implants. Bone and bone substitutes. CDA J. 1988:16(1):56-65

6. Oliveira RC, Sicca CM, Silva TL, Cestari TM, Oliveira DT, Buzalaf MAR et al. Efeito da temperatura de desproteinização no preparo de osso cortical bovino microgranular. Avaliação microscópica e bioquímica da resposta celular em subcutâneo de ratos. Rev FOB. 1999;7(3/4):85-93.

7. Taga MLL. Análise histológica e radiográfica do potencial osteopromotor da membrana de cortical óssea bovina no reparo de defeito ósseo de tamanho crítico na calvária de cobaia $(\mathrm{Ca}$ via porcellus) [Dissertação de Mestrado]. Bauru: Faculdade de Odontologia da USP; 2004.

8. Sciadini MF, Dawson JM, Johnson KD. Evaluation of bovine-derived bone protein with a natural coral carrier as a bone-graft substitute in a canine segmental defect model. J Orthop Res. 1997;15(6):844-57.

9. Kalkura SN, Anee TK, Ashok M, Betzel C. Investigations on the synthesis and crystallization of hydroxyapatite at low temperature. Biomed Mater Eng. 2004;14(2):581-92.

10. Werner J, Linner-Krcmar B, Friess W, Greil P. Mechanical properties and in vitro cell compatibility of hydroxyapatite ceramics with graded pore structure. Biomaterials. 2002;23(21):4285-94.

11. Carotenuto G, Spagnuolo G, Ambrosio L, Nicolais L. Macroporous hydroxyapatite as alloplastic material for dental applications. J Mater Sci Mater Med. 1999;10(10/11):671-6.

12. Misch CE. Contemporary implant dentistry. $2^{\text {nd }}$ ed. St. Louis: CV Mosby; 1999.

13. Tampieri A, Celotti G, Sprio S, Delcogliano A, Franzese S. Porosity-graded hydroxyapatite ceramics to replace natural bone. Biomaterials. 2001;22(11):1365-70. nancial support received from CNPq (CT-Saude, process number 504.808/2004-4), Capes, Fapesp (Grant $n^{\circ}$ 99/10655-5 and 01/10707-7), Faperj and FINEP (Grant nº. 01.04.0469.00).

14. Thaller SR, Hoyt J, Dart A, Borjeson K, Tesluk H. Repair of experimental calvarial defects with Bio-Oss particles and collagen sponges in a rabbit model. J Craniofac Surg. 1994;5(4):242-6.

15. Tadic D, Epple M. A thorough physicochemical characterisation of 14 calcium phosphate-based bone substitution materials in comparison to natural bone. Biomaterials. 2004;25(6):987-94.

16. Tadic D, Peters F, Epple M. Continuous synthesis of amorphous carbonated apatites. Biomaterials. 2002;23(12):25539.

17. Landi E. Densification behavior and mechanisms of synthetic hydroxyapatite. J Eur Cer Soc. 2000;(20):2377-87.

18. Blank BS, Levy AR. Combined treatment of a large periodontal defect using GTR and DFDBA. Int J Periodontics Restorative Dent. 1999;19(5):481-7.

19. Zitzmann NU, Naef R, Scharer P. Resorbable versus nonresorbable membranes in combination with Bio-Oss for guided bone regeneration. Int J Oral Maxillofac Implants. 1997;12(6):844-52.

20. Burg KJ, Porter S, Kellam JF. Biomaterials development for bone tissue engineering. Biomaterials. 2000;21(23):234759.

21. Houser BE, Mellonig JT, Brunsvold MA, Cochran DL, Meffert RM, Alder ME. Clinical evaluation of inorganic bovine xenograft with a bioabsorbable collagen barrier in the treatment of molar furcation defects. Int J Periodontics Restorative Dent. 2001;21(2):161-9.

22. Yamada S, Shima N, Kitamura H, Sugito H. Effect of porous xenographic bone graft with collagen barrier membrane on periodontal regeneration. Int J Periodontics Restorative Dent. 2002;22(4):389-97.

23. Su-Gwan K, Hak-Kyun K, Sung-Chul L. Combined implantation of particulate dentine, plaster of Paris, and a bone xenograft (Bio-Oss) for bone regeneration in rats. J Craniomaxillofac Surg. 2001;29(5):282-8.

24. Le Geros RZ. Calcium phosphate biomaterials: preparation, properties and biodegradations. In: Wise DL [editor]. Encyclopedic Handbook of Biomaterials and Bioengineering. New York: Marcel Dekker; 1995. v. 1, pt. A, p. 1429-63.

25. Elliot JC. Structure and chemistry of the apatite and other calcium orthophosphates. Amsterdam: Elsevier; 1994. 